\title{
Determination of thermal characteristics of standard and improved hollow concrete blocks using different measurement techniques
}

\author{
Caruana, C.; Yousif, C.; Bacher, Peder; Buhagiar, S.; Grima, C.
}

Published in:

Journal of Building Engineering

Link to article, DOI:

10.1016/j.jobe.2017.09.005

Publication date:

2017

Document Version

Peer reviewed version

Link back to DTU Orbit

Citation (APA):

Caruana, C., Yousif, C., Bacher, P., Buhagiar, S., \& Grima, C. (2017). Determination of thermal characteristics of standard and improved hollow concrete blocks using different measurement techniques. Journal of Building Engineering, 13, 336-346. https://doi.org/10.1016/j.jobe.2017.09.005

\section{General rights}

Copyright and moral rights for the publications made accessible in the public portal are retained by the authors and/or other copyright owners and it is a condition of accessing publications that users recognise and abide by the legal requirements associated with these rights.

- Users may download and print one copy of any publication from the public portal for the purpose of private study or research.

- You may not further distribute the material or use it for any profit-making activity or commercial gain

- You may freely distribute the URL identifying the publication in the public portal 


\section{Author's Accepted Manuscript}

Determination of Thermal Characteristics of Standard and Improved Hollow Concrete Blocks using Different Measurement Techniques

C. Caruana, C. Yousif, P. Bacher, S. Buhagiar, C. Grima

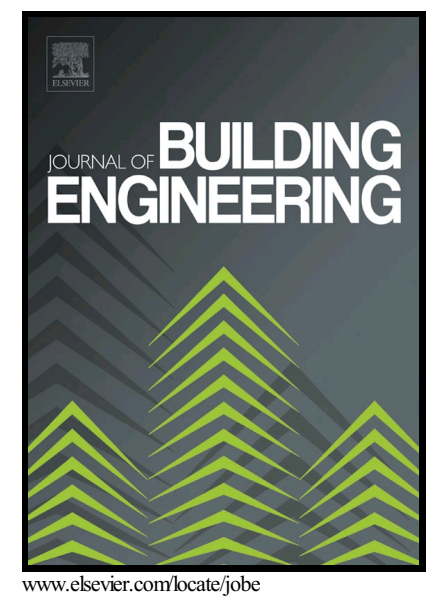

PII: S2352-7102(16)30307-2

DOI: $\quad$ http://dx.doi.org/10.1016/j.jobe.2017.09.005

Reference: JOBE325

To appear in: Journal of Building Engineering

Received date: 28 October 2016

Revised date: 28 July 2017

Accepted date: 10 September 2017

Cite this article as: C. Caruana, C. Yousif, P. Bacher, S. Buhagiar and C. Grima, Determination of Thermal Characteristics of Standard and Improved Hollow Concrete Blocks using Different Measurement Techniques, Journal of Building Engineering, http://dx.doi.org/10.1016/j.jobe.2017.09.005

This is a PDF file of an unedited manuscript that has been accepted for publication. As a service to our customers we are providing this early version of the manuscript. The manuscript will undergo copyediting, typesetting, and review of the resulting galley proof before it is published in its final citable form. Please note that during the production process errors may be discovered which could affect the content, and all legal disclaimers that apply to the journal pertain. 


\title{
ACCEPTED MANUSCRIPT
}

\section{Determination of Thermal Characteristics of Standard and Improved}

\section{Hollow Concrete Blocks using Different Measurement Techniques}

\author{
C. Caruana ${ }^{\mathrm{a}}$, C. Yousif $^{\mathrm{a}^{*}}$, P. Bacher ${ }^{\mathrm{b}}$, S. Buhagiar ${ }^{\mathrm{c}}$, C. Grima $^{\mathrm{d}}$
}

anstitute for Sustainable Energy, University of Malta, Barrakki Street, Marsaxlokk, MXK1531, Malta
bDTU Compute, Technical University of Denmark, 2800 Kgs. Lyngby, Denmark
${ }^{\mathrm{b}}$ Faculty of the Built Environment, University of Malta, Tal-Qroqq, Msida, MSD2080, Malta
${ }^{\mathrm{d}}$ Galea Curmi Engineering Services Ltd., Mican Court No.5, J.F. Kenedy Square, Victoria, Gozo, VCT 2580, Malta

*Corresponding author. Tel.: +356-23407831. charles.yousif@um.edu.mt

\section{Abstract}

The lighter weight, improved thermal properties and better acoustic insulation of hollow-core concrete blocks are few of the characteristics that one encounters when comparing them to traditional Maltese globigerina limestone solid blocks. As a result, hollow concrete blocks have recently been in greater demand. However, their transmittance, or U-value, is still quite high and does not meet the minimum energy requirements for constructing new buildings. This paper is focused on the investigation of the thermal properties of a new building block, developed as part of a nationally-funded research project ThermHCB, with the aim of improving the U-value of such blocks without changing their compressive strength, physical dimensions or manufacturing process. Measurement techniques were applied to obtain comparative values of the thermal transmittance for standard and improved HCBs, using different EN and draft standards. Compressive testing was carried out concurrently in order to ensure that the minimum benchmark compressive strength was reached. The comparison between these results provides information on the reliability of the methodologies used to determine the thermal properties of building elements in-situ, without having to conduct such tests in a laboratory hot box setup.

\section{Abbreviations}

U-value, Value of thermal transmittance (W/m²K); HCB, Hollow concrete block; HVAC, Heating, ventilation and air-conditioning; ARX-model, Autoregressive model with exogenous inputs; HFM, Heat flow meter method; IRM, Infra-red method; OA, Orthogonal array; LECA, Lightweight expanded clay aggregate; EPS, Expanded polystyrene; q, Heat flux $\left(\mathrm{W} / \mathrm{m}^{2}\right) ; \mathrm{k}$, Thermal conductivity (W/mK); DT, Temperature differential (K); L, Thickness of material (m); G, Global solar radiation $\left(\mathrm{W} / \mathrm{m}^{2}\right)$; ACF, Auto-correlation function; $\mathrm{CCF}$, Cross-correlation function; $\mathrm{H}$, Sum of UA-value and convection losses (W/K); UA-value, Value of the product of the U-value and the area perpendicular to the direction of heat transmittance $(\mathrm{W} / \mathrm{K})$; A, Area perpendicular to the direction of heat transmittance $\left(\mathrm{m}^{2}\right)$; HLC, Total heat loss coefficient (W/K)

Keywords: hollow-core concrete block; heat flow; infra-red; insitu; building envelope; Malta

\section{Introduction}




\section{ACCEPTED MANUSCRIPT}

In a report issued by the International Energy Agency 1991 "Energy Efficiency and the Environment", it is stated that in most countries, construction activities cover between 1 and $3 \%$ of the existing buildings per annum. It is no surprise that as stated by Goldberg et al. in 1988 "Energy and a Sustainable World", it is cheaper to save an extra unit of energy rather than generating it, considering long-term energy prices.

For the population of Southern Europe, the indoor comfort conditions during summer have always been a priority. Inhabitants from warm and hot climates have always endeavoured to find solutions to reduce indoor temperatures. Hence, the choice of wall materials has been one vital parameter on which summer comfort depends. The thermal properties of building envelopes can be deduced from heat transmission data as declared by manufacturers, which are generally obtained by laboratory measurements or numerical simulations. Whilst thermal conductivity figures of insulation materials are well established, those for components of the building envelope - such as masonry blocks - are less defined. In such cases, the in-situ measurement of thermal transmittance is crucial to have in hand for a correct evaluation of the building envelope's thermal behaviour. This is not to say that laboratory assessment is not a robust methodology, but evaluating the thermal transmittance of building walls under real operating conditions has its usefulness. In-situ measurements of thermal transmittance of buildings have become essential, more so, in high-energy performing buildings, since the variance in value between actual and laboratory/numerically calculated one, affects the building's performance and its economic cost-benefit analysis.

According to the National Statistics Office - Malta (News Release 189/2014), the electrical energy generation and consumption in Malta over the past decade was on average 2.2 million megawatt hours annually. The local percentage of electrical energy use in buildings (residential and commercial) accounts for a considerable proportion of around 60\%. For this reason, building energy conservation is important for Malta's sustainable development. It is interesting to note that approximately $20 \%$ of all electricity generated occurs in July and August when the temperatures are highest. In order for people to live and work comfortably in their buildings, temperatures are controlled using HVAC systems, thus contributing towards higher energy use. The building envelope plays a vital role in reducing energy consumption in buildings, by regulating the amount of heat flowing through it. In 2012, a 4.6\% increase in electricity demand excluding renewables was recorded. Reacting to this growth simply by increasing the generation capacity could lead to economic and environmental consequences [1]. Figure 1 below shows a graphical interpretation of electricity generation in Malta between 2004 and 2015.

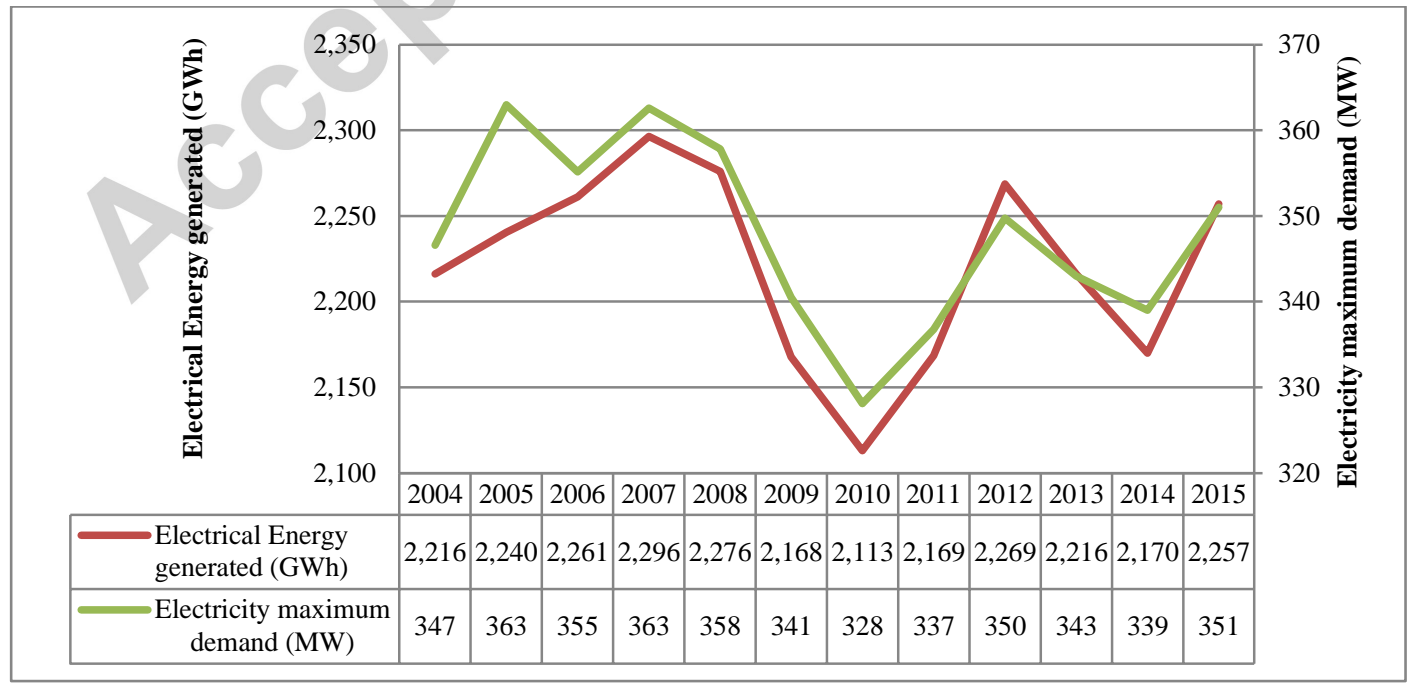

Figure 1: Electricity generation in Malta between 2004 and 2015 [Compiled from data available at the Regulator for Energy and Water Services (ex-Malta Resources Authority)] 
Changes to the masonry units are one of the necessary measures that need to be undertaken if energy savings and efficiency are to be achieved. It is therefore no surprise that thermal characteristics of building envelopes are nowadays under increased scrutiny with the ever growing international concerns over energy and resource conservation. Many studies have been done and are still being carried out to provide new building materials and devise simple ways of constructing appropriate building envelopes with the right thermo-physical properties. The concrete technology can be easily adapted to suit special needs of users by modifying design parameters such as mix proportions, constituent materials and water/cement ratios. Work, on methods of measurements and specific material production, carried out by various researchers has been taken into account for this study. Following is a summary of those works that enabled the organisation and conflation of information as the basis for the testing methodologies adopted for this research study [1].

1. The concept of the full scale testing created by the international collaboration in the context of IEA ECBCS [2], was also applied in this specific research work, whereby two in-situ test cells were constructed in order to analyse the thermal behaviour of different hollow concrete blocks concurrently.

2. The active and passive method procedures, presented in the work of Fazio et al. [3], were influential in opting for the active method chosen for this research methodology, in order to overcome the elaborate equipment required for the passive procedure. Moreover, as seen in the works of Yesilata et al. [4], given that the purpose of the work to be carried out for this study was to compare the U-values of standard and improved HCB walls, the same methodology was implemented for all samples thus eliminating the possible variation in results obtained from applying either of the methods mentioned above.

3. The use of thermal imaging to identify locations and extent of thermal bridging, as well as the use of thermal paste ensuring good contact of the heat flux sensor with the test wall, as applied in the works of Byrne et al. [5], were both adopted in the work carried out for this study. Thermal imaging was used in order to certify that the location on the wall chosen for placement of the heat flux sensor was representative of the heat flow through the entire wall. Methods of setup used in the work of Fang et al. [6] were also applied in the testing methodology of this research. Heat flux sensors were installed making use of masking tape and placed either on the web or on the cavity of the HCBs.

4. In this study, the U-values, obtained from in-situ measurements, were compared to results obtained from hot box measurements and numerical modelling. Similar comparisons were carried out by Dr Paul Baker [7] as presented in his research report. In this way, it was possible to obtain relevant conclusions about estimated thermal transmittances, when comparing theoretical values with actual in-situ measurements. S. Pulis [8] proposed that this behavioural characteristic is taken into account and theoretical values are compared with actual measured values of resistances of HCBs.

5. One-dimensional heat flow was assumed for this study based on the supposition taken by N. Vella [9], whereby he stated that given the dimensions of the experimental test cells, one could assume that heat flow in one direction is very close to the real behaviour achieved. Another important factor deriving from Vella's work was the issue of handling and positioning of HCBs on site. In the study presented here, this matter was given prime importance and that is why experiments were carried out on the same shape and dimensions of prototype block with emphasis only on improving the mix of the actual building block. 
6. Importance of environmental infiltration rates, as discussed in the work of Becker [10], was particularly considered in this research. In order to limit the amount of air infiltration rates inside the test cells, attention to workmanship at the time of construction was given utmost importance, especially during the placement of mortar on the horizontal and vertical joints. This was also ensured by making use of the service of the same builder throughout the whole course of this research study.

7. In the ThermHCB project, the research partners Galea Curmi Engineering Services Ltd. followed the study presented in the publication of Kato et al. [11] to set up the methodology for the infrared testing, results of which were used in this research work. Prime importance was given to the time period of testing, taken between midnight and 06:00 hours in order to avoid direct solar radiation.

8. The experimental structure used in the study of Thouvenel [12] was similar in principle to the in-situ infrared testing setup used for this study. Amongst other considerations, one ought to mention the aspect ratio of the test wall when compared to its thickness vis-a-vis one dimensional analysis, the importance of the heat dispersion onto the test wall when it comes to the position of the heater in the field of vision of the camera, as well as the use of a fan to keep a homogeneous internal air temperature.

9. The reviewed study of Morales et al. [13] is similar in principle to part of the research work described in this paper. The existing geometrical properties of the HCB and the method of assembly were kept the same and the study was directed towards the relationship between the conductivity of the material and the thermal transmittance of the wall. In this way, results can be presented in a way so as to enable designers and builders to choose the most appropriate block according to the necessary parameters for any particular project. Figure 2 below [13] is a graphical illustration of results obtained through this study.

10. Statistical modelling, as presented by Bacher et al. [14], was utilised in this study through the use of R-program. Results obtained from the statistical modelling were then compared to in-situ and laboratory results in order to validate the methodologies adopted for the research work carried out. 


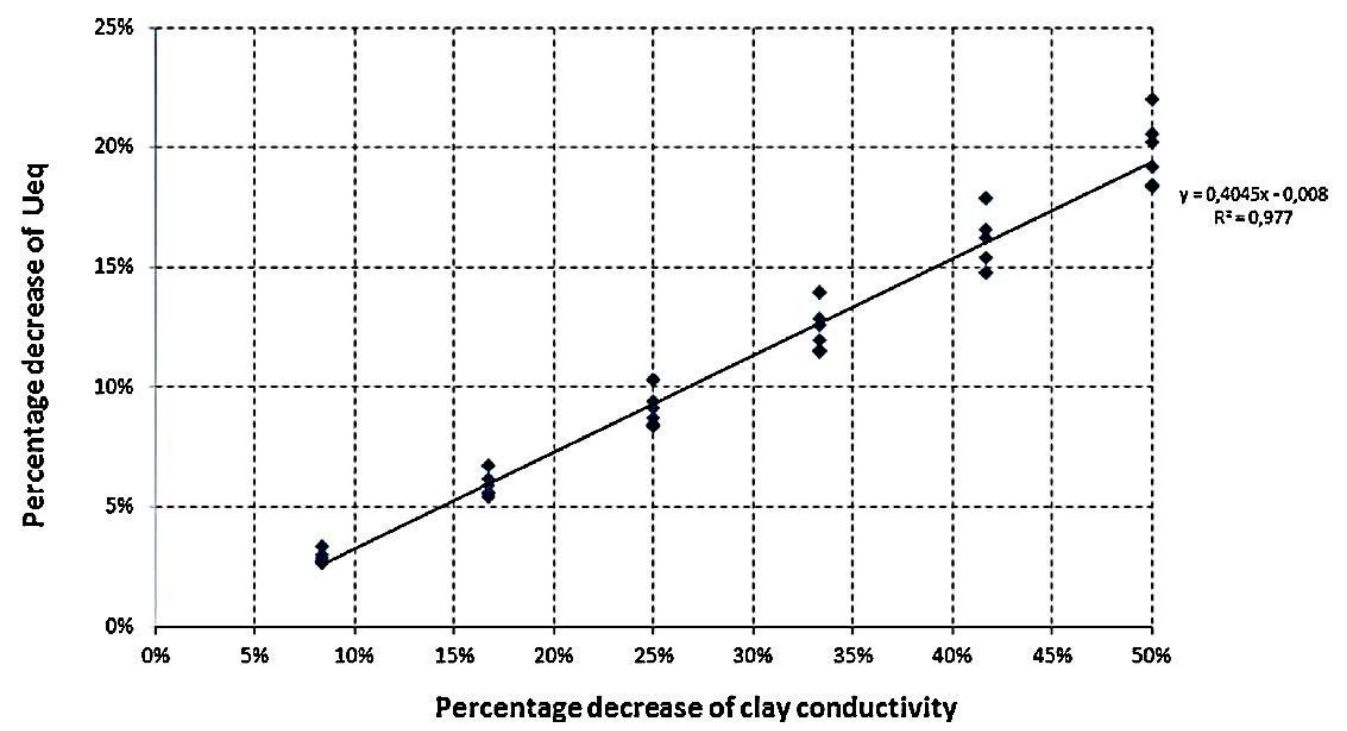

Figure 2: Percentage decrease of equivalent thermal transmittance $\left(\mathrm{U}_{\mathrm{eq}}\right)$ vs. percentage decrease in clay conductivity [13]

ThermHCB Project (for which blocks have been developed and tested in this study) is another attempt of ongoing local research, promoting the development of higher energy efficient building materials, in order to achieve Malta's energy efficiency targets by 2020. In this project, the potential applicability of ThermHCB blocks as thermally enhanced building blocks was investigated. ThermHCB (part-financed by the Malta Council for Science and Technology, co-ordinated by Galea Curmi Engineering Services Ltd in partnership with R. A. \& Sons Manufacturing Ltd and the University of Malta) was a project aimed at developing a building block with enhanced thermal properties keeping the standard local dimensions of the HCB with its current structural strength. This new block differs from existing 'insulated concrete blocks' available on the local market, due to the fact that:

(i) it does not vary in size from the standard HCB,

(ii) it offers the same structural strength and integrity as the standard HCB,

(iii) it provides enhanced thermal properties when compared to the standard HCB,

(iv) it requires no special tools or training for builders to use, and

(v) it needs no change in the manufacturing process or machinery used to produce the standard HCBs.

The reason for keeping the same dimensions was based on ergonomics as well as local workmanship techniques. The aim of the project was to obtain a satisfactory block with low heat transmittance characteristics without impacting manufacturing process lines or local building workmanship techniques. When studying possible new materials, it is necessary to take into account the application of scientific information to the designs of objects and environment for human use. Therefore, aspects such as mass and shape of the HCB are essential. Well-designed blocks can result in a reduction of fatigue/discomfort of builders, when carrying construction material, thus maximizing productivity.

The use of various in-situ and laboratory-based heat measurement techniques was utilised to determine and compare the thermal characteristics of existing local standard hollow concrete blocks and thermally improved prototypes being developed by ThermHCB industrial partner, R. A. \& Sons 


\section{ACCEPTED MANUSCRIPT}

Manufacturing Ltd. The thermal testing results were carried out on test walls making use of standard and prototype blocks and constructed using two different setups:

(i) In a hot box under laboratory conditions, and

(ii) In test cells constructed in-situ.

In this research study, three thermal testing methods were investigated in order to establish the correlation of the results obtained from each measurement technique. The testing methodologies were based on:

The Hot Box Method: using Document BS EN1934:1998: Thermal Performance of Buildings - Determination of thermal resistance by hot box method using heat flow meter - Masonry;

The Heat Flow Meter Method: using ISO Document 9869:1994: Part 1: Thermal Insulation - Building Elements - In-situ measurement of thermal resistance and thermal transmittance; and

The Infra-red Method: using the ISO Draft Working Document 9869: Part 2: Thermal Insulation - Building Elements - In-situ measurement of thermal resistance and thermal transmittance.

Besides the above, the guidelines [21] developed in IEA Annex 58 were used to formulate a suitable autoregressive model with exogenous inputs (ARX-model) for some series of the in-situ data. Furthermore, R-scripts [23] from the guidelines were used for calculation of the U-value.

All thermal experiments were carried out at the Institute for Sustainable Energy of the University of Malta in Marsaxlokk (Malta). Two test cells were constructed externally, in order to measure the thermal characteristics of the different HCBs under in-situ conditions. These results were then compared to those obtained from the hotbox inside the laboratory. Measured and established design values of thermal conductivity were used for calculations and results compared indicating the possible reasons for differences. The comparison between the test results obtained from the two insitu measurement techniques and those obtained from the hot-box method and the numerical analysis were used to establish the reliability of the same in-situ methods of testing.

\section{Theory and Calculations}

\subsection{General concept of research methodology}




\section{ACCEPTED MANUSCRIPT}

A flow chart representing the main process of the research methodology adopted in this study is shown in Figure 3 below.

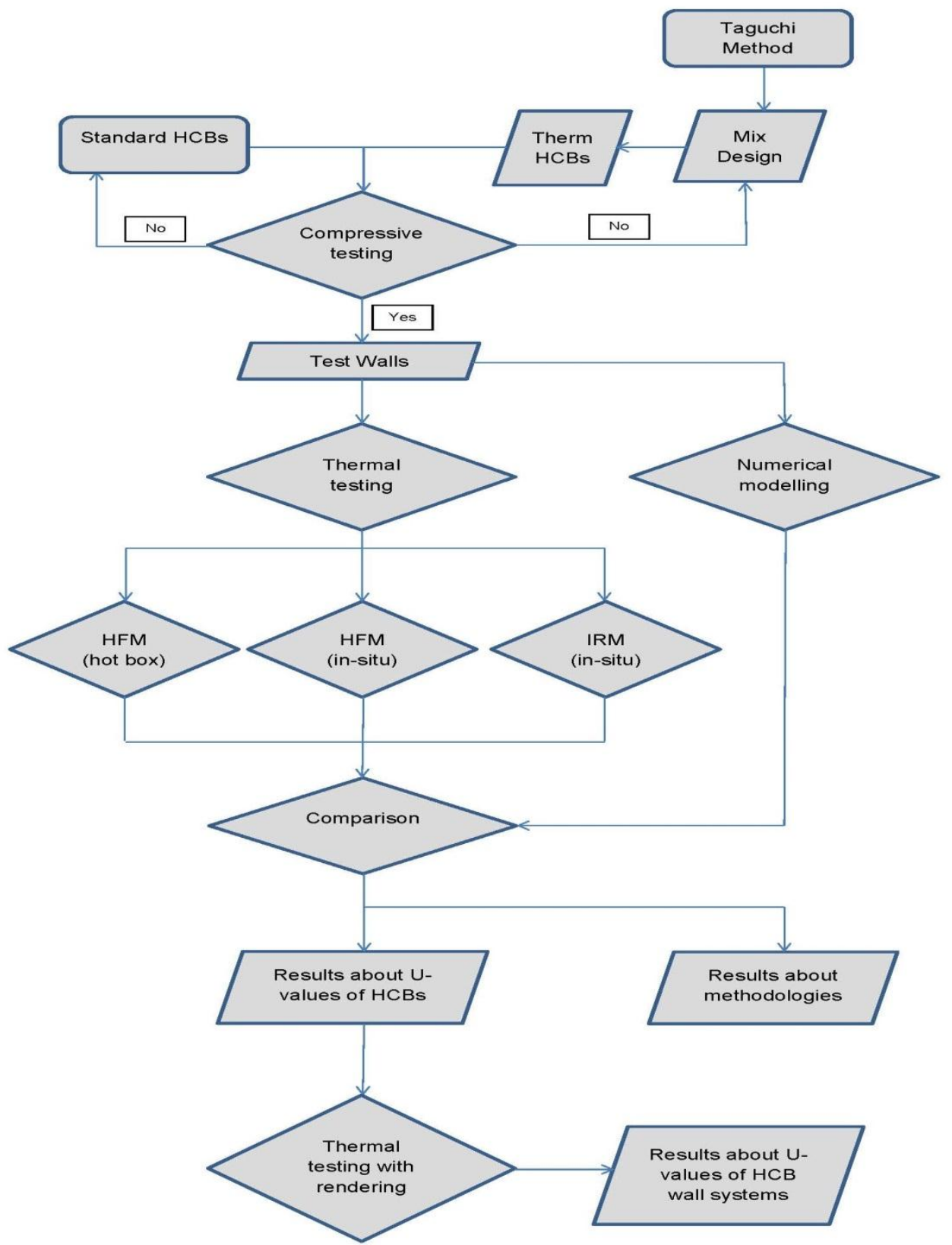

Figure 3: Main process of research methodology [1]

\subsection{Test material characterisation}

The block's production materials included expanded clay aggregates, in order to achieve the minimum target thermal improvement of at least $10 \%$ over standard HCB. Moreover, a new rendering mix was tested to gauge its thermal properties as opposed to normal cement rendering. The factors which have been varied were parameters that constitute the mix proportions. A study of correlation among different parameters was carried out and a clustering of those parameters, based on the same 


\section{ACCEPTED MANUSCRIPT}

physical principles, was done in order to reduce the number of design parameters. The Taguchi Method, based on 'Orthogonal Arrays' (OA) [15], was chosen to help in the planning and conduction of experiments throughout the research work with the aim of keeping the variance of the output as low as possible.

Compressive strength and thermal characteristics, in conjunction with plasticity of mix for ease of block manufacturing were the three main factors of importance in designing the mix of the ThermHCB block. The first batches of the prototype concrete mixes included expanded clay aggregate and perlite as a partial replacement of natural aggregates and Portland cement. The use of perlite in the mixes was later disregarded, since it was found to be mostly influential in improving the compressive strength rather than reducing the thermal transmittance value. The coarse/fine aggregates and sand used for the manufacturing of HCBs in these experiments were obtained locally. The cement used in all the mixes was an ASTM Type 1 and the light expanded clay aggregate (LECA) used was imported from the nearby island of Sicily, in Italy. The materials used for all batches were homogenized except for the ratio between materials, as shown in Table 1. This was done so as to better correlate between the specimens. The testing experiments were carried out and the respective compressive strength and thermal characteristic results recorded. The best possible levels of mix proportions were investigated for the maximisation of compressive strength and thermal resistance. From these results, bar charts were plotted to denote the percentage contribution of each factor and level on the compressive and thermal performance. The resultant elite group of parameters originating from the start population was then reconsidered until the optimal mix design was achieved.

Sixteen batches of masonry units were sampled and tested, of which seven batches were composed of normal concrete masonry units and nine batches of ThermHCBs of various mix proportions. It is to be noted that single density $230 \mathrm{~mm}$ HCBs typically have concrete mix thickness of at least $10 \mathrm{~mm}$ less than those of double density $230 \mathrm{~mm}$ HCBs. In other words, the air cavities are larger and the compressive strength is lower than double density HCB. Figure 4 below shows photos of the HCBs manufactured and various batches stacked up on pellets after they had been tested in-situ and in the hot box setups. Table 1 shows the dimensionless sample mix designs manufactured by R. A. \& Sons Manufacturing Ltd. The exact quantities cannot be disclosed to protect intellectual property rights.
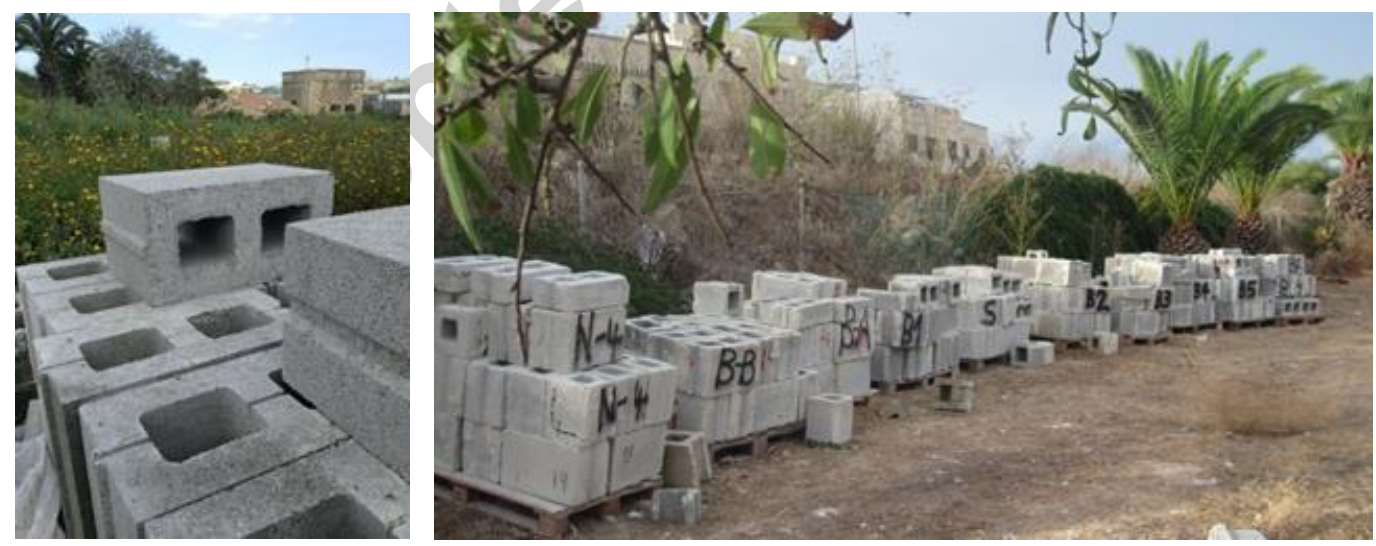

Figure 4: Masonry units used for testing at the Institute for Sustainable Energy, Marsaxlokk [1] 


\section{ACCEPTED MANUSCRIPT}

Table 1: Dimensionless sample mix designs manufactured by R. A. \& Sons Manufacturing Ltd. [1]

\begin{tabular}{|c|c|c|c|c|c|c|c|}
\hline \multirow{3}{*}{\multicolumn{2}{|c|}{ Type of mix }} & \multirow{3}{*}{ Batch No } & \multicolumn{5}{|c|}{ Materials } \\
\hline & & & \multirow[b]{2}{*}{ Sand } & \multirow{2}{*}{$\begin{array}{c}\text { Coarse } \\
\text { aggregate }\end{array}$} & \multirow[b]{2}{*}{ Cement } & \multicolumn{2}{|c|}{ LECA } \\
\hline & & & & & & $\begin{array}{c}\text { LECA } \\
(2 / 3-3 / 8)\end{array}$ & $\begin{array}{c}\text { LECA } \\
\text { structural }\end{array}$ \\
\hline \multirow{7}{*}{ Standard HCBs } & \multirow{4}{*}{ 9" single density } & HCB-N & 1.00 & 1.00 & 0.44 & -4 & - \\
\hline & & HCB-N1 & 1.00 & 1.00 & 0.47 & - & - \\
\hline & & HCB-N2 & 1.00 & 1.00 & 0.50 & & - \\
\hline & & HCB-N3 & 1.00 & 1.00 & 0.53 & _- & - \\
\hline & \multirow{3}{*}{$9 "$ double density } & HCB-N4 & 1.00 & 1.00 & 0.53 & - & - \\
\hline & & HCB-N5 & 1.00 & 1.00 & 0.56 & - & - \\
\hline & & HCB-N6 & 1.00 & 1.00 & 0.59 & - & - \\
\hline \multirow{9}{*}{ ThermHCBs } & \multirow{6}{*}{ 9" single density } & HCB-1 & 0.42 & 0.43 & 0.87 & 0.80 & - \\
\hline & & $\mathrm{HCB}-2$ & 0.73 & 0.43 & 0.87 & 0.80 & - \\
\hline & & HCB-3 & 0.75 & 0.38 & 0.87 & 0.90 & - \\
\hline & & $\mathrm{HCB}-4$ & 0.34 & 0.34 & 0.87 & 1.00 & - \\
\hline & & HCB-5 & 0.44 & 0.44 & 1.00 & 0.80 & - \\
\hline & & HCB-6 & 0.48 & 0.48 & 1.00 & 1.00 & - \\
\hline & \multirow{3}{*}{$9 "$ double density } & HCB-7 & 0.74 & 0.41 & 0.87 & - & 1.00 \\
\hline & & HCB-8 & 0.78 & 0.45 & 0.87 & - & 0.88 \\
\hline & & HCB-10 & 0.70 & 0.18 & 0.72 & 0.72 & - \\
\hline
\end{tabular}

\subsection{Compression testing procedures}

Compression testing was carried out at the Laboratory of the Faculty for the Built Environment, University of Malta. The concrete masonry units were tested for compression strength in accordance with BS 6073-2:1981 notwithstanding the fact that this standard has been withdrawn and replaced by BS 6073-2:2008, refer to Figure 5 [16] below. The decision to use the fibre board method, stipulated in BS 6073-2:1981, instead of the mortar capping method, of BS 6073-2:2008, was reinforced by the recommendations found in BS 6073-2:1981 clause B.6 which states:

"The fibre board test is likely to give values for compressive strength of block lower than those obtained from test on mortar capped blocks. However, the results of fibre board tests may be taken to indicate the compressive strength of the blocks unless an acceptable relationship between mortar cap tests and fibre board tests has been established for a particular type and strength of block being tested."

This testing was done in order to ensure that comparison of thermal values of the different HCBs was carried out on a common platform of characteristic compressive strengths. This also ensured that thermal improvements, applied to the mix designs of blocks used for this study, did not jeopardise the load-bearing capacity of the same blocks. 


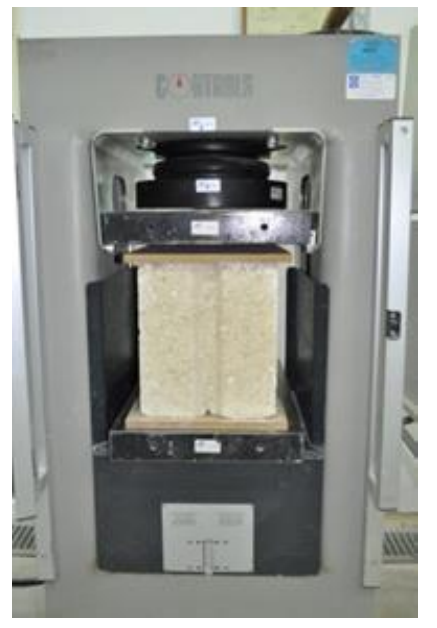

Figure 5: Setup for compressive strength testing (fibre board rapid test BS 6073-1:1981) [16]

From Table 1 below, one can observe that samples manufactured under standard production (HCB-N, HCB-N1, HCB-N2, HCB-N3, HCB-N4, HCB-N5 and HCB-N6) obtained a mean strength (after 28 days of air curing) between $6.6 \mathrm{~N} / \mathrm{mm}^{2}$ and $11.5 \mathrm{~N} / \mathrm{mm}^{2}$. On the other hand, the prototype ThermHCBs (HCB-1, HCB-2, HCB-3, HCB-4, HCB-5, HCB-6, HCB-7, HCB-8 and HCB-10) reached values of mean compressive strengths of up to $12.1 \mathrm{~N} / \mathrm{mm}^{2}$ (for HCB-8). HCB-4 registered the lowest mean compressive strength of $3.7 \mathrm{~N} / \mathrm{mm}^{2}$.

Table 2: Compressive strength results of concrete masonry units [1]

\begin{tabular}{|c|c|c|c|c|c|c|c|c|}
\hline & $\begin{array}{c}\text { Mean } \\
\text { Strength } \\
\mathrm{N} / \mathrm{mm}^{2}\end{array}$ & $\begin{array}{c}\text { Standard } \\
\text { Deviation } \\
\mathrm{N} / \mathrm{mm}^{2}\end{array}$ & $\begin{array}{c}\text { Maximum } \\
\text { Strength } \\
\mathrm{N} / \mathrm{mm}^{2}\end{array}$ & $\begin{array}{c}\text { Minimum } \\
\text { Strength } \\
\mathrm{N} / \mathrm{mm}^{2}\end{array}$ & $\begin{array}{l}\text { Range } \\
\mathrm{N} / \mathrm{mm}^{2}\end{array}$ & $\begin{array}{c}\text { Mean } \\
\text { Weight } \\
\text { kg }\end{array}$ & $\begin{array}{c}\text { Minimum } \\
\text { Weight } \\
\mathrm{kg}\end{array}$ & $\begin{array}{c}\text { Maximum } \\
\text { Weight } \\
\mathrm{kg}\end{array}$ \\
\hline $\mathrm{HCB}-\mathrm{N}$ & 6.6 & 0.72 & 8.24 & 5.01 & 3.23 & --- & --- & -- \\
\hline $\mathrm{HCB}-\mathrm{N} 1$ & 7.2 & 0.69 & 8.70 & 6.10 & 2.60 & --- & --- & --- \\
\hline $\mathrm{HCB}-\mathrm{N} 2$ & 9.2 & 1.47 & 13.10 & 5.60 & 7.50 & 35.1 & 34.4 & 37.7 \\
\hline $\mathrm{HCB}-\mathrm{N} 3$ & 7.5 & 1.32 & 9.70 & 4.80 & 4.90 & 33.4 & 32.7 & 34.4 \\
\hline $\mathrm{HCB}-\mathrm{N} 4$ & 7.9 & 0.85 & 9.20 & 6.03 & 3.18 & 40.0 & 38.3 & 42.0 \\
\hline $\mathrm{HCB}-\mathrm{N} 5$ & 9.9 & 1.53 & 14.59 & 7.30 & --- & 43.1 & 41.1 & 46.8 \\
\hline $\mathrm{HCB}-\mathrm{N} 6$ & 11.5 & 1.13 & 14.34 & 9.75 & --- & 43.2 & 41.5 & 45.6 \\
\hline HCB - 1 & 7.6 & 0.91 & 8.77 & 5.80 & 2.97 & --- & --- & --- \\
\hline HCB - 2 & 6.5 & 0.85 & 7.97 & 4.05 & 3.92 & --- & --- & --- \\
\hline HCB - 3 & 5.1 & 0.65 & 6.16 & 3.99 & 2.16 & --- & --- & --- \\
\hline НCB - 4 & 3.7 & 0.47 & 4.90 & 2.60 & 2.30 & 24.3 & 23.4 & 25.9 \\
\hline HCB - 5 & 4.1 & 0.59 & 5.50 & 3.10 & 2.30 & 26.5 & 25.7 & 28.2 \\
\hline HCB - 6 & 5.5 & 0.62 & 6.60 & 4.20 & 2.40 & 26.9 & 26.2 & 28.4 \\
\hline HCB - 7 & 9.9 & 1.70 & 12.69 & 6.92 & 5.77 & 35.5 & 33.5 & 37.5 \\
\hline HCB - 8 & 12.1 & 1.15 & 14.03 & 9.82 & 4.22 & 37.5 & 35.7 & 39.9 \\
\hline $\mathrm{HCB}-10$ & 7.5 & 0.74 & 10.09 & 5.81 & --- & 33.0 & 32.1 & 35.2 \\
\hline
\end{tabular}

\subsection{Test walls}

All HCBs used to construct the test walls were manufactured and supplied by R. A. \& Sons Manufacturing Ltd. The HCBs used for testing were stored under the same ambient conditions, so as to reduce error variations due to moisture content in specimens. They were kept on timber pellets, covered by thick plastic sheets, outside in the open air at the Institute for Sustainable Energy, Marsaxlokk. 


\section{ACCEPTED MANUSCRIPT}

The mortar used to provide the bonding strength between the masonry blocks was the general purpose mortar produced with a mix proportion of cement, sand and water and prepared according to need on-site. The same builder was engaged to build all the walls in order to reduce variations in mode of laying the blocks and applying mortar. The walls were constructed with six full courses and an extra cut-to-size block placed at the top. Images in Figure 6 below illustrate the test wall setups insitu and in the hot box.
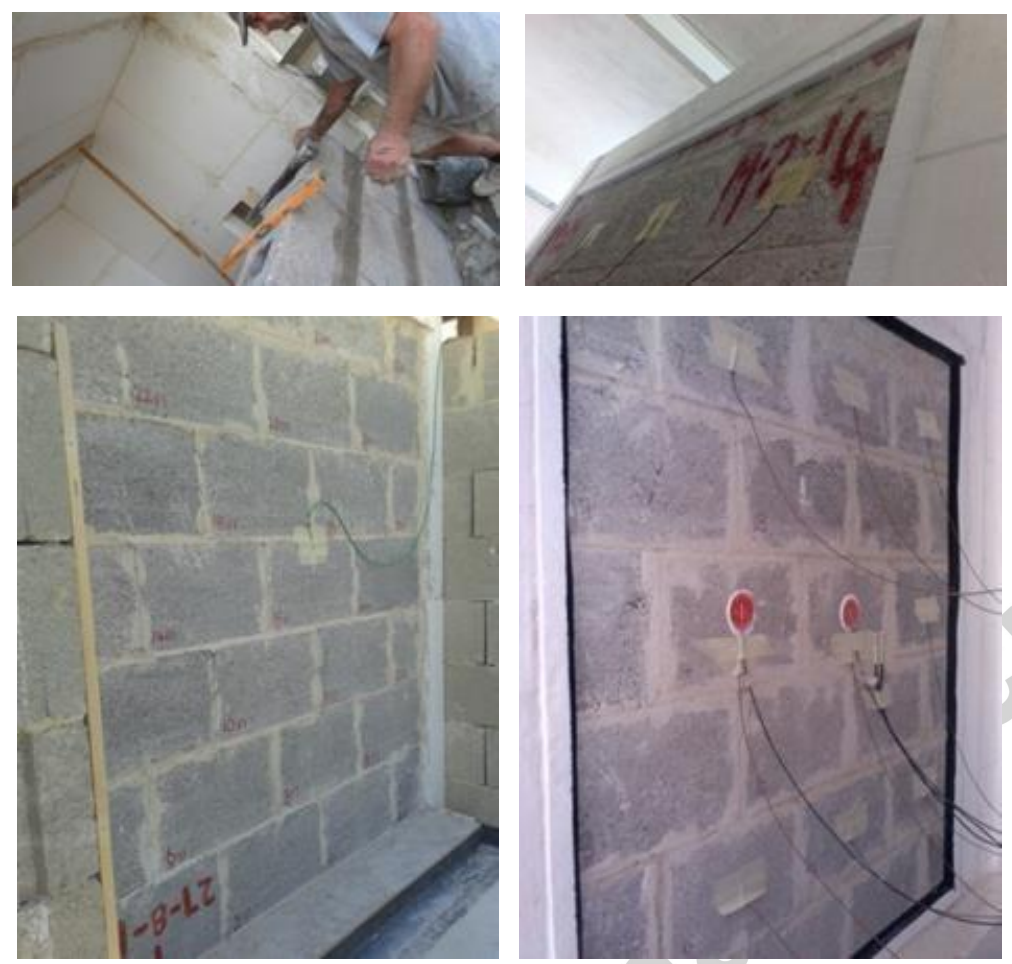

Figure 6: In-situ (left-hand side top and bottom) and hot box (right-hand side top and bottom) test wall setups [1]

\subsection{Insitu test cells}

Two field test cells were constructed in order to carry out in-situ thermal experiments. Figure 7 [17] and Figure 8 [16] below show the design of the setup of the two fully insulated test cells. The test wall models, with dimensions of $1.65 \mathrm{~m}$ by $1.90 \mathrm{~m}$, were composed of $230 \mathrm{~mm}$ cementbased hollow-core block masonry having a north-facing orientation. Fans on the inside compartment of the test cells were used to circulate air inside, whilst the flow of air on the outside was left to natural convection. This was obtained by placing a polycarbonate shielding at a distance of approximately

$0.25 \mathrm{~m}$ from the test wall with lower and upper openings to allow for natural ventilation. This shielding was also used in order to protect the test walls from direct wind and rain thus making it possible to assume that all tests were being carried out under similar conditions, in as far as solar radiation, wind and humidity ingress control was concerned. 


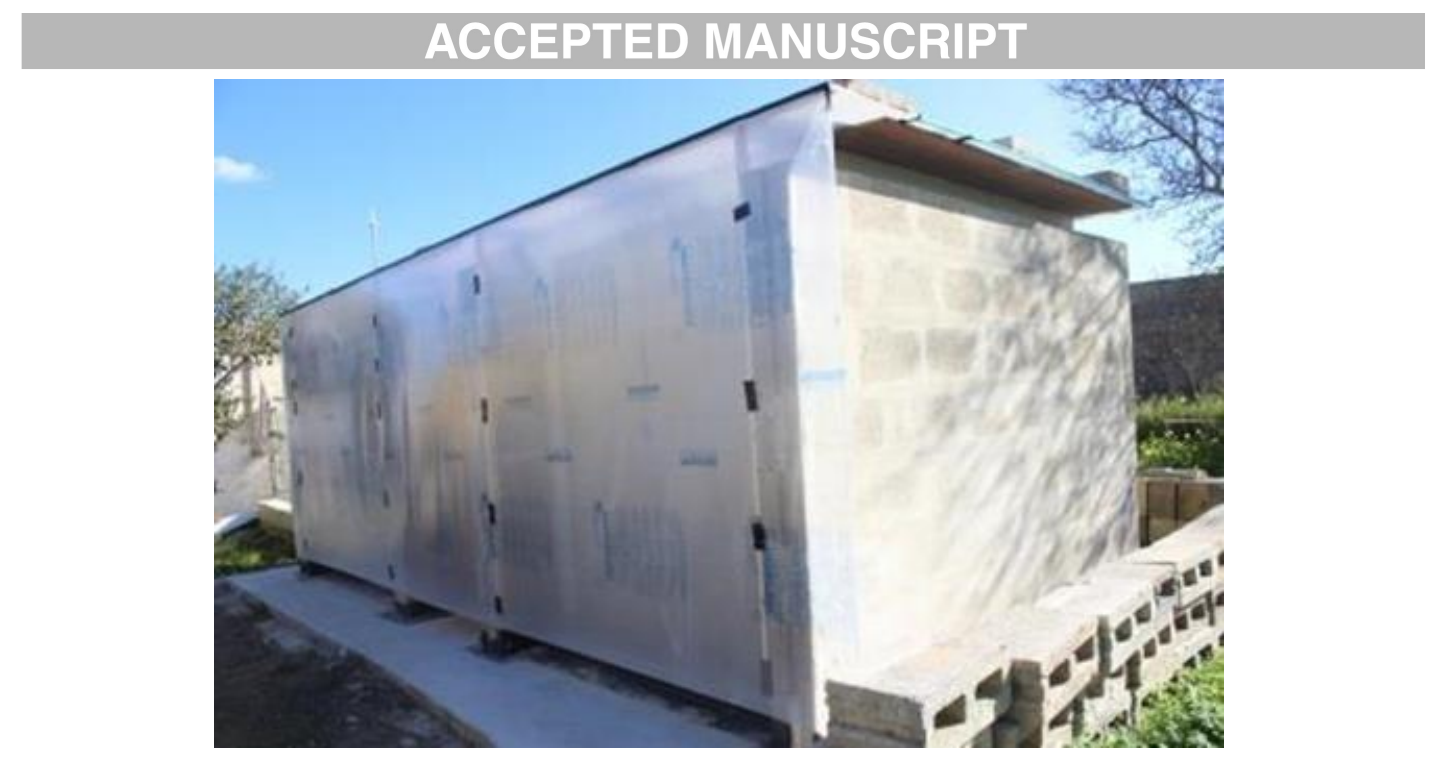

Figure 7: Northern side view of in-situ test cells with polycarbonate sheeting protecting the test walls [17]

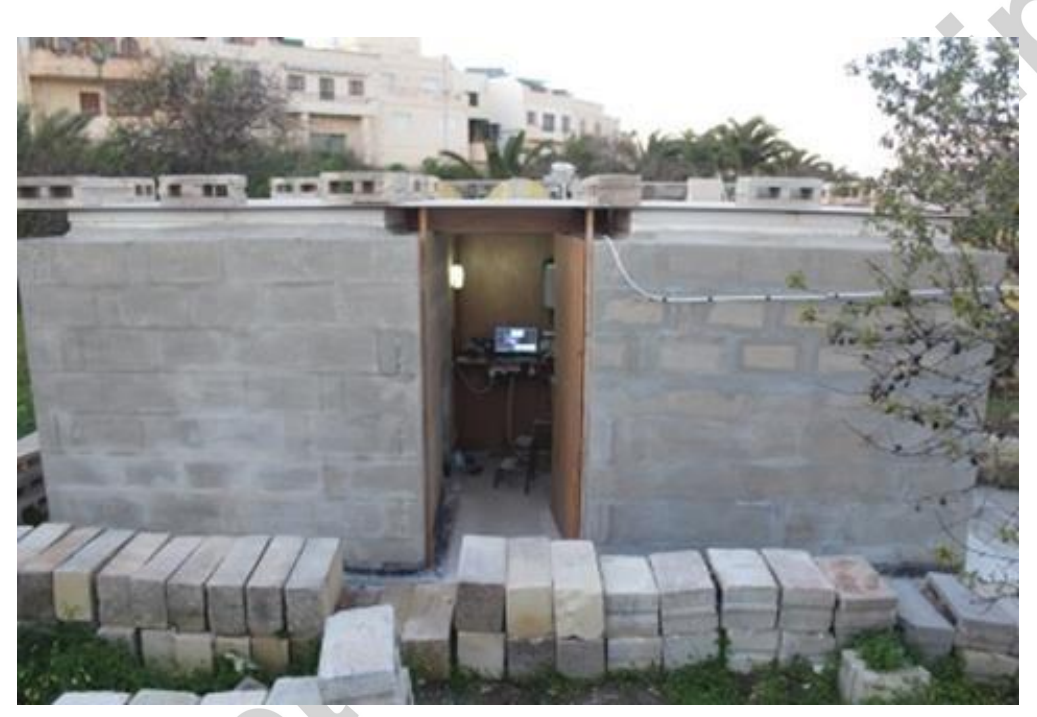

Figure 8: Southern side view of in-situ test cells showing the data monitoring equipment area [16]

One test cell (Test Cell 2, on the left-hand side, Figure 11) had standard local HCB walls under monitoring, whilst the other test cell (Test Cell 1, on the right-hand side, Figure 11) was used to monitor different prototype HCB walls. To maintain functional equivalency of both the standard and prototype wall models, and hence ensure similar test room enclosures (roof, floor and external walls) of which the test wall formed part, it was necessary to carefully insulate the top, bottom and sides of the room model. This was achieved through the use of made-to-measure expanded polystyrene (EPS) 3 -sided boxes (for the two test cells) made out of sheets of $150 \mathrm{~mm}$ thickness with a density of $15 \mathrm{~kg} / \mathrm{m}^{3}$ complemented with a tongue and grooved system and further sealed at the joints using expanded polystyrene beads and an acrylic-based sealer to reduce thermal bridging at these junctions. Waterproofing of the wall-floor edges was also carefully taken care of, in order to control ingress of water from the outside into the test cells. This was done using self-adhesive waterproofing membrane around all the perimeter of both test cells. 


\subsection{The hot-box}

A schematic isometric illustration of the hot-box setup can be seen in Figure 9 below.

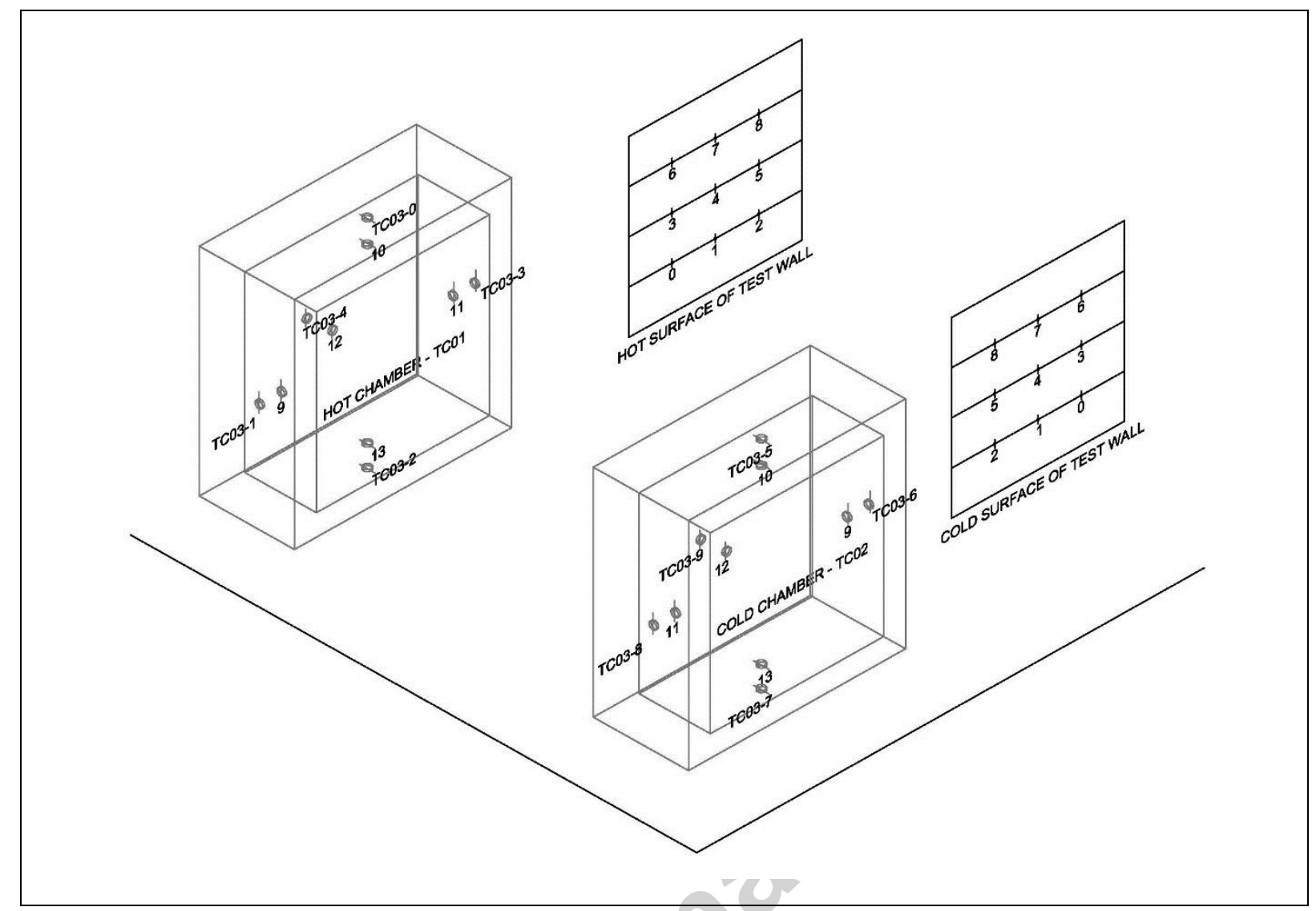

Figure 9: Schematic illustration of hot-box setup [1]

The technical specifications of the hot box setup are given in Table 2 hereunder.

Table 3: Technical specifications of environmental chamber [1]

\begin{tabular}{ll}
\hline \multicolumn{1}{c}{ Parameter } & \multicolumn{1}{c}{ Values } \\
\hline Cold chamber temperature range & $+16^{\circ} \mathrm{C} \pm 1{ }^{\circ} \mathrm{C}$ \\
Hot chamber temperature range & $+40^{\circ} \mathrm{C} \pm 1{ }^{\circ} \mathrm{C}$ \\
Maximum specimen dimensions & $1.65 \mathrm{~m}$ wide $\times 1.90 \mathrm{~m}$ high $\times 0.23 \mathrm{~m}$ thick \\
Dimensions of whole environmental chamber & $2.75 \mathrm{~m}$ wide $\times 3.82 \mathrm{~m} \mathrm{long}$ 2.75m high \\
\hline
\end{tabular}

The setup consisted of one environmental chamber, made up of two separate compartments, situated inside the workshop of the Institute for Sustainable Energy, in Marsaxlokk. The enclosure of the climate chambers was composed of timber panels insulated with expanded polystyrene, supported on two separate timber structures. The cold chamber was kept fixed, whilst the hot chamber rested on wheels and could therefore be easily moved around. The use of steel clamps ensured that the environmental chamber was well sealed, reducing heat leakages through the system. Between the hot and cold chambers, single leaf masonry walls measuring $1.65 \mathrm{~m}$ by $1.90 \mathrm{~m}$ by $0.23 \mathrm{~m}$ (length by height by thickness), satisfying the minimum requirements stipulated by the British Standard BS EN 1934:1998, were built. These test walls composed of various types of HCBs were based on standard size two-cavity units of $480 \mathrm{~mm}$ x $280 \mathrm{~mm}$ x $230 \mathrm{~mm}$ and already used for in-situ testing. They were constructed in a staggered fashion, in exactly the same way as they were built in-situ (this 


\section{ACCEPTED MANUSCRIPT}

was possible through a numbering system of each and every block used). This ensured that all measurements read in the hot box coincided with those taken in-situ.

\subsection{Monitoring and analysis}

\subsubsection{Heat flow meter method}

At steady state, the heat flux and temperatures at both layer surfaces of the HCB test walls are related by the following equation:

$$
q=\frac{k \Delta T}{L}
$$

whereby,

$\mathrm{q}=$ heat flux in $\mathrm{W} / \mathrm{m}^{2}$

$\mathrm{k}=$ thermal conductivity in $\mathrm{W} / \mathrm{mK}$

$\Delta \mathrm{T}=$ temperature differential in $\mathrm{K}$

$\mathrm{L}=$ thickness of the material through which heat flows in metres (m)

Therefore,

$$
k=q \cdot \frac{L}{\Delta T}
$$

The input variables were the monitored heat flux and temperatures on the inner and outer surface of the test wall taken through the solid material (web) of the block. The resulting output variable was the thermal conductivity. The readings were taken at specified intervals and over a period sufficiently long to take into account the thermal capacity of the wall model and reduce the variations encountered in the quasi-steady state of the testing stages. Moving averages of heat flux and corresponding temperature difference, taken over spans of three hours, were computed over quasi-steady state periods. This enabled the calculation of the thermal conductivity using Equation 2 above. The thermal resistances were then calculated by using the Combined Method Technique (the Parallel and Isothermal methods of calculation), as presented in the Technical Guidance F, Appendix E [18].

A minimum temperature gradient of approximately $10^{\circ} \mathrm{C}$ between the inside and outside surface temperatures has been adopted, as recommended by Desogus et al. [19] and Byrne et al. [5], in order to reduce the error regime when collecting and analysing the data being monitored. A low temperature gradient across the thickness of the test walls would have given rise to a lower difference between transverse and lateral heat flow. This would mean that uni-directional analysis would not be possible given that lateral heat flows would have a substantial effect when compared to the transverse heat flow taking place across the walls.

\subsubsection{Infrared method}

A FLIR T640 infrared camera was used to capture thermograms of the HCB under investigation every two seconds. This allowed a satisfactory number of thermal images to be recorded over a period of time covering the cyclic temperatures of the test cell, generated by the resistance heating element inside. At a later stage, these thermal images were processed using ThermaCAM Researcher Pro 2.10, which allows in-depth analysis of thermograms by accessing temperature data from a large array of manageable measurement functions such as area and line measurement functions. Figure 13 below illustrates the sections of the HCB investigated. Area measurement functions were drawn over these areas of interest. From the thermograms captured, one could observe 


\section{ACCEPTED MANUSCRIPT}

temperature contrasts between the three defined sections of the HCB. Before extracting temperature data from thermograms, parameters related to atmospheric attenuation and emission such as temperature of the atmosphere, relative humidity and distance between the camera and the target object were set in the "object parameters" settings in the ThermaCAM Researcher Pro 2.10 software. Once this step was computed, ThermaCAM Researcher automatically compensated the influence of these parameters on the values obtained, thus yielding corrected temperature surface measurements of the tested regions. The U-value of the hollow concrete block was determined by setting the area measurement function on the whole surface area of the masonry unit and then averaging the individual U-values [20].

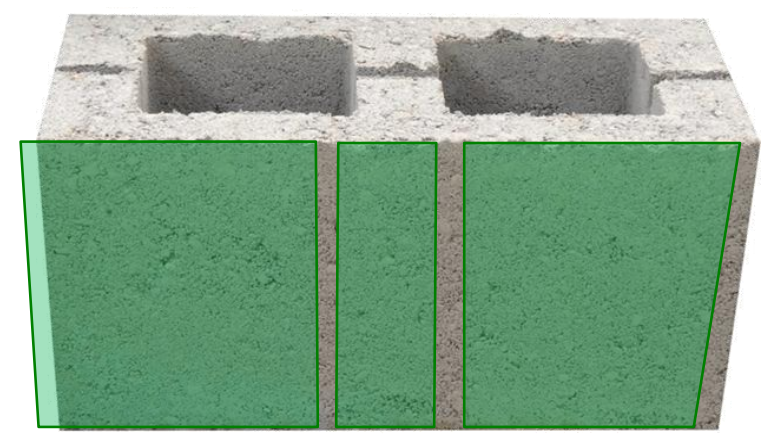

Figure 10: Areas of HCB being investigated for the determination of U-value [1]

\subsubsection{Statistical modelling}

The use of physical knowledge of the in-situ test cells in conjunction with statistical timeseries models was used to theoretically investigate the thermal behaviour of the prototype HCBs under dynamic conditions. The data used was that collected in-situ over 10-minute averages. The data was read and resampled to 1 hour average values. The inputs and outputs of the models were the heat flux, the internal and external temperature of the test wall surface and the global solar radiation. The parameters of the models were the overall heat loss coefficient, HLC (a measure of both transmission and convection losses denoted by $H$, hence a sum of the UA-value and convection losses) and the solar transmittance per square metre denoted by $g$. Given the assumption of uni-directional heat flow through the test wall models built in the test cell under examination, the following ARX-model [21] was used to analyse dynamically the set of variables available.

$$
F(B) q_{t}=\omega_{i}(B) T_{t}^{i}+\omega_{e}(B) T_{t}^{e}+\omega_{G}(B) G_{t}+e_{t}
$$

where $F(B)$ is the output (or $\mathrm{AR}$ ) polynomial of order $p$ in the backshift operator $B$, and similarly the input polynomials $w_{\mathrm{i}}(\mathrm{B}), w_{\mathrm{e}}(\mathrm{B})$ and $w_{\mathrm{G}}(\mathrm{B})$ are polynomials of order $\mathrm{s}_{\mathrm{Ti}}, \mathrm{s}_{\mathrm{Te}}$ and $\mathrm{s}_{\mathrm{G}}$. The model parametrization has heat flow rate $(q)$ as output, and the internal/external temperature $\left(T^{i}, T^{e}\right)$ and global solar radiation $(G)$, as input. A linear steady-state model $(p=0)$, following the equation below:

$$
q_{t}=\omega_{i} T_{t}^{i}+\omega_{e} T_{t}^{e}+\omega_{G} G_{t}+e_{t}
$$

was fitted to the data gathered. The residuals auto-correlation function (ACF) and cross-correlation function (CCF) to the inputs were plotted as shown in Figure 10 below. 


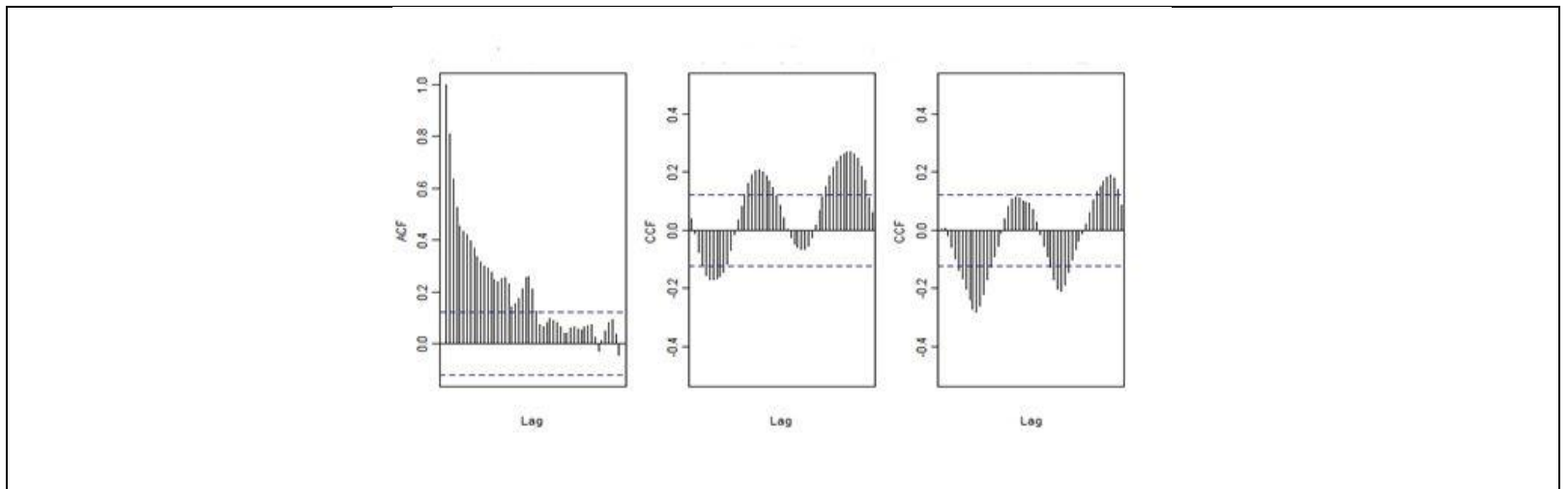

Figure 11: Plots of the residuals of ACF and CCF for $p=0$ [1]

The model order was increased until the residuals did not indicate a sequence of correlated values. Once the final model was chosen, the values of $H$ and $g A$, together with their standard deviation were estimated. The $H$ value obtained was equivalent to the sum of $U A$-value $(\mathrm{W} / \mathrm{K})$ and convection losses. This value was then compared to the values obtained from the other experimental techniques in order to establish the relationship between all methods. The $g A$-value (W/K) was used to study the effect of solar radiation on the heat flux. This was done in order to establish that the assumption made in this research study: that of placing the test wall north-oriented would reduce the effect of solar radiation, holds.

\section{Results and Discussions}

Table 4 below gives results of the thermal transmittance of the various batches obtained under the three different experimental techniques. Specific values of surface resistance coefficients (as presented in the guidelines of Technical Guidance F [18]) were added to the measured values when calculating the thermal transmittance. The experimental error analysis and overall measurement uncertainties were derived from the individual measurement uncertainties. A detailed explanation of the derivations can be found in Appendix A of the thesis of C. Caruana [1].

Similar to what is seen in the study of Yesilata et al. [22], whereby the addition of strip/circular rubber in concrete exhibited lower heat loss when compared to standard concrete, test results in this research study showed that almost all the new batches showed better thermal behaviour than the reference concrete batches. A possible explanation for this result is the fact that the expanded clay particles have lower $\mathrm{k}$-values than the local natural aggregates which they partially replaced, hence reducing the thermal conductivities of the modified mixes. From Figure 11 below, it is noted that for both single and double density HCBs, increased aggregate replacement with LECA content practically always resulted in a decrease in U-value. The distribution of data on the graph shows that, another factor must influence the heat flow through the concrete blocks apart from the material's thermal conductivity. This could be related to the distribution of air voids in the whole concrete mix.

Table 4: Thermal transmittances of HCB mix design samples [1]

\begin{tabular}{|c|c|c|c|c|c|c|c|c|c|c|}
\hline \multirow{2}{*}{\multicolumn{2}{|c|}{ Type of mix }} & \multirow[b]{2}{*}{ Batch No } & \multicolumn{8}{|c|}{ U-value $\left(\mathbf{W} / \mathbf{m}^{2} \mathbf{K}\right)$} \\
\hline & & & $\begin{array}{c}\text { HFM } \\
\text { (hot } \\
\text { box) }\end{array}$ & $\begin{array}{l}\text { Error } \\
( \pm)\end{array}$ & $\begin{array}{l}\text { HFM } \\
\text { (in- } \\
\text { situ) } \\
\end{array}$ & $\begin{array}{c}\text { Error } \\
( \pm)\end{array}$ & $\begin{array}{c}\text { IRM } \\
\text { (in- } \\
\text { situ) } \\
\end{array}$ & $\begin{array}{c}\text { Error } \\
( \pm)\end{array}$ & $\begin{array}{l}\text { ARX- } \\
\text { models }\end{array}$ & $\begin{array}{c}\text { Error } \\
( \pm)\end{array}$ \\
\hline \multirow{3}{*}{ Standard HCBs } & \multirow{3}{*}{ 9" single density } & HCB-N ${ }^{1}$ & 2.296 & 0.025 & 2.311 & 0.025 & - & - & - & - \\
\hline & & HCB-N1 & 2.415 & 0.026 & 2.443 & 0.026 & 2.298 & 0.299 & - & - \\
\hline & & HCB-N2 & 2.399 & 0.026 & 2.500 & 0.027 & 3.226 & 0.419 & - & - \\
\hline
\end{tabular}




\section{ACCEPTED MANUSCRIPT}

\begin{tabular}{|c|c|c|c|c|c|c|c|c|c|c|}
\hline & & HCB-N3 & 2.422 & 0.026 & 2.357 & 0.025 & 3.028 & 0.393 & - & - \\
\hline & \multirow{3}{*}{ 9" double density } & HCB-N4 & 2.287 & 0.024 & 2.401 & 0.026 & 3.215 & 0.418 & - & - \\
\hline & & HCB-N5 & 2.333 & 0.025 & 2.489 & 0.027 & - & - & 2.762 & 0.032 \\
\hline \multirow{10}{*}{ ThermHCBs } & & HCB-N6 & 2.376 & 0.025 & 2.740 & 0.030 & 4.042 & 0.525 & - & - \\
\hline & \multirow{6}{*}{$9 "$ single density } & HCB-1 & 2.251 & 0.024 & 2.289 & 0.024 & 2.333 & 0.303 & - & - \\
\hline & & HCB-2 & 2.264 & 0.024 & 2.159 & 0.023 & 1.913 & 0.249 & - & - \\
\hline & & $\mathrm{HCB}-3$ & 2.210 & 0.024 & 2.197 & 0.023 & 2.056 & 0.267 & - & - \\
\hline & & HCB-4 & 2.072 & 0.023 & 2.156 & 0.023 & 2.470 & 0.321 & - & - \\
\hline & & HCB-5 & 2.203 & 0.024 & 2.140 & 0.023 & 2.933 & 0.381 & - & - \\
\hline & & HCB-6 & 2.189 & 0.024 & 2.195 & 0.023 & 2.585 & 0.336 & - & - \\
\hline & \multirow{3}{*}{ 9" double density } & HCB-7 & 2.110 & 0.023 & 2.198 & 0.023 & 2.717 & 0.353 & - & - \\
\hline & & HCB-8 & 2.191 & 0.023 & 2.386 & 0.026 & 3.205 & 0.416 & 2.571 & 0.036 \\
\hline & & HCB-10 & 2.103 & 0.022 & 2.174 & 0.023 & 3.244 & 0.4217 & 2.283 & 0.025 \\
\hline
\end{tabular}

Notes: ${ }^{1}$ The value for HFM (in-situ) has been averaged out for all the testing carried out during the period February 2014 - March 2015.

HFM stands for heat flow meter method.

IRM stands for infrared method.

ARX stands for autoregressive model with exogenous inputs.

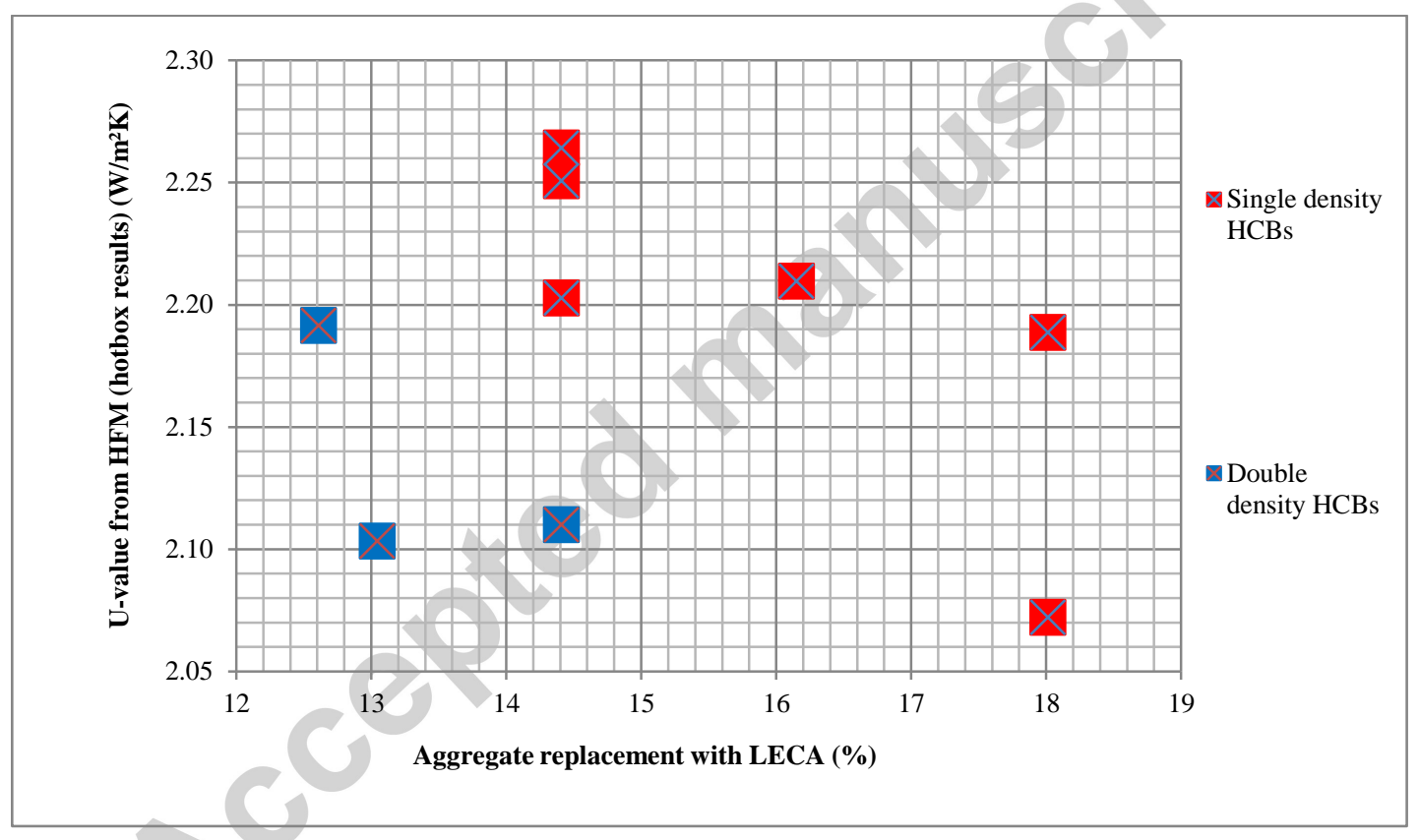

Figure 12: Relationship of thermal transmittance with LECA content replacement [1]

Figure 12 below shows the U-values obtained for the different single and double density HCBs used for the wall models tested under the three experimental methodologies, together with the associated margin of error for each result, expressed as a high-low limit line for each bar graph. 

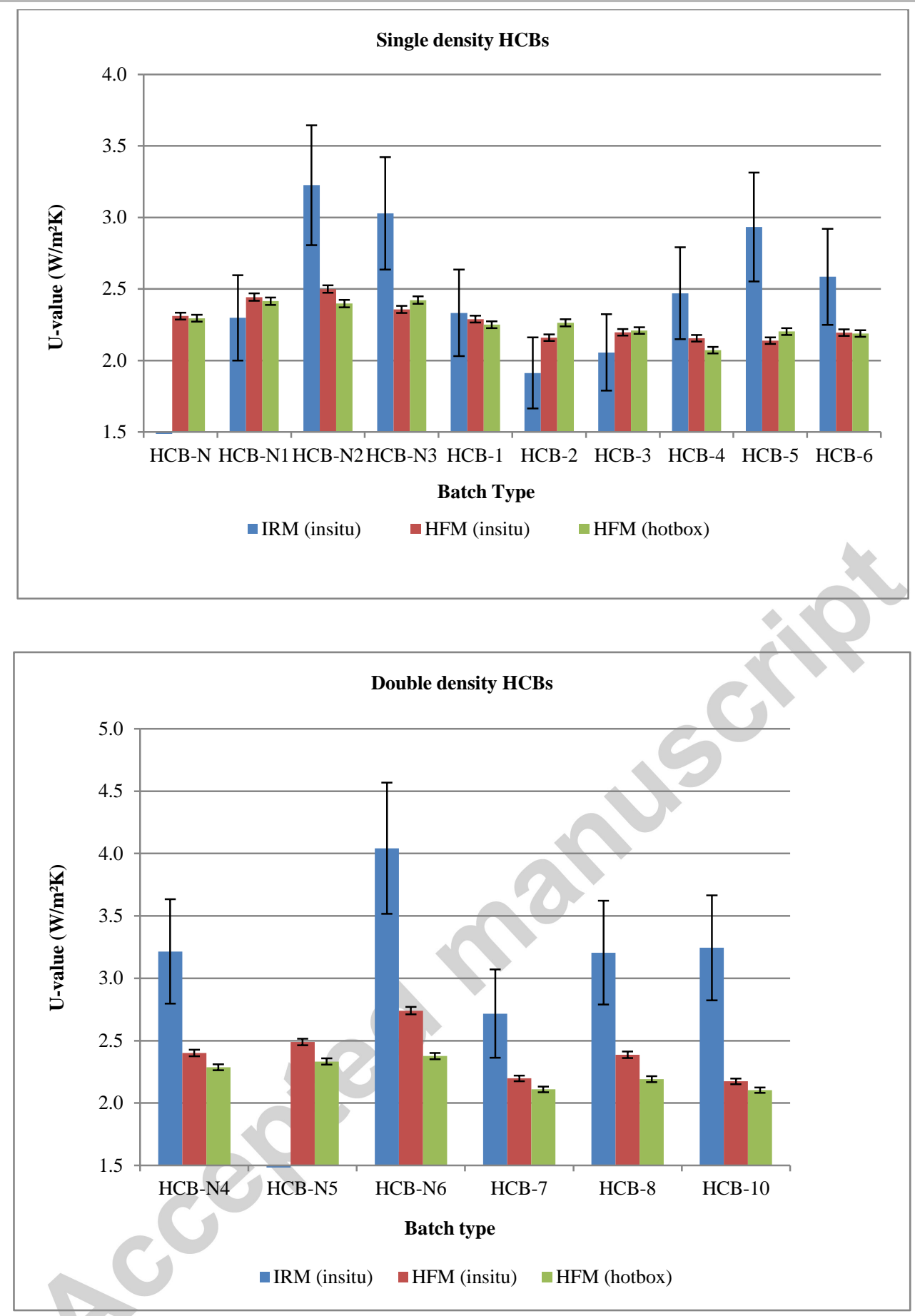

Figure 13: Thermal properties of batched samples [1]

The results indicate a trend showing that the more representative of the real conditions the testing methodology is (such as in-situ testing), the higher is the U-value. In fact, the IRM results tended to yield the highest values. This may be attributed to the fact that firstly, the infrared testing was carried out in-situ and secondly, that rather than considering the heat flux occurring over one point on the HCB (as is the case with the heat flow meter method), the IRM takes into account a bigger area of the HCB. The data represented in Figure 12 above can be very useful as a tool for builders and designers to choose the most appropriate method of measurement according to the degree of accuracy to which they want to construct or design their buildings. As one would expect, the lowest U-values were obtained using the best thermal block represented by HCB-10, however, this does not 


\section{ACCEPTED MANUSCRIPT}

imply that the other test batches are not useful for construction. In fact, one can opt to have a better Uvalue HCB with a lower value of compressive strength for a location which is going to be used for non-structural purposes.

The results of the three measurement techniques together with the ones obtained from ARXmodels for batches HCB-8, HCB-10 and HCB-N5 are graphically illustrated in Figure 13 below. It is to be noted that the infrared test on HCB-N5 was not carried out by Galea Curmi Engineering Services Ltd due to time constraints. To this end, comparison of results to the IRM values could not be made for this batch.

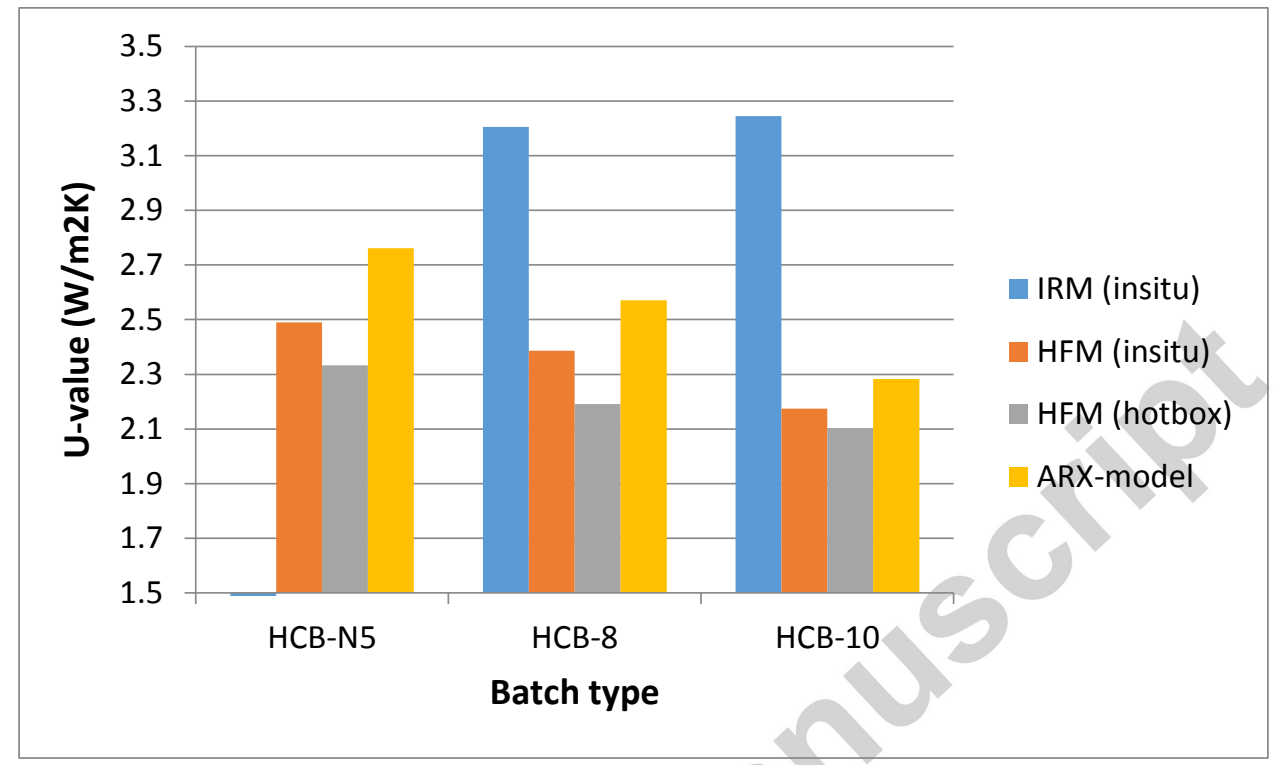

Figure 14: Comparison of U-value results from HFM, IRM and ARX-models [1]

Comparison of these four procedures yielded some interesting results. The U-values obtained from the ARX-models always tended to be slightly higher than the values obtained using the HFM method (even though the data used for the statistical modelling was that collected for the insitu HFM method). An explanation for this could be the fact that using the HFM method of testing meant averaging out the dynamic effect of the in-situ measurement. Further studies could be carried out taking into consideration humidity levels which might have been a key factor for this difference between the two measurement techniques. The U-values obtained using the heat flow meter method both in-situ and in laboratory conditions were very close to each other but differed from those obtained using IR thermography. The latter results were derived over a period of 6 hours, whereas results from the heat flow meter methods of testing were achieved by means of continuous time series of measurements over weekly periods. This implies that much more data was evaluated in the case of the heat flow meter methods possibly resulting in more precise results.

In Figure 14 below, the heat flux readings for HCB-10, obtained using the HFM in-situ method, are presented. Results in this figure show that deviations of up to $20 \%$ exist between the average measurements taken over one week and the measurements taken over the last day of testing. The mean heat flux values obtained through the week measurements tended to be lower than values corresponding to the last day of reading. This meant that higher U-values would be obtained which explains why results from the IRM analysis (which was based on data gathered over the last day of the testing period) tended to be higher than those obtained by HFM techniques. 


\section{ACCEPTED MANUSCRIPT}

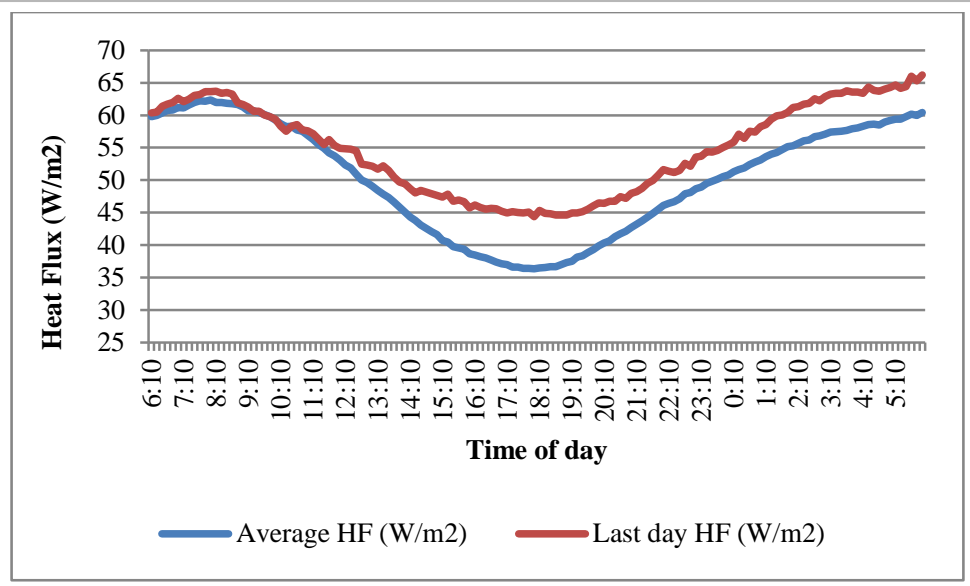

Figure 15: Weekly and daily comparison of resultant HFM in-situ U-values [1]

\section{Conclusions}

The experimental investigations undertaken in this study were conducted on both existing standard local HCBs as well as on a new type of lightweight masonry block: ThermHCB. The main conclusions of the study carried out are summarised hereunder [1]:

1. The optimal solution presented in this work was exhibited when testing walls with prototype $230 \mathrm{~mm}$ double density HCBs (HCB-10) having a thermal transmittance (U-value) of 2.174 $\pm 0.023 \mathrm{~W} / \mathrm{m}^{2} \mathrm{~K}$ (in-situ HFM value). Each block weighed approximately $33 \mathrm{~kg}$, with dimensions of circa $458 \mathrm{~mm}$ wide by $280 \mathrm{~mm}$ high by $230 \mathrm{~mm}$ thick and an approximate area of two holes as a percentage of gross area equal to $28 \%$. The percentage thermal improvement of HCB-10 over the standard $230 \mathrm{~mm}$ double density HCB (HCB-N5) was of $12.7 \%$.

2. For HCB-10, the replacement of expanded clay as aggregate in the tested sample reduced the unit weight by approximately $23 \%$ and reached improved thermal insulation performances of approximately $12.7 \%$ when compared to HCB-N5. Given that this achievement was reached without losing on the reference characteristic compressive strength value (7.5 MPa), the comparative study carried out concludes that ThermHCB blocks exhibit a potential as a lightweight building block offering significant savings not only in labour and transportation but also as load-bearing thermally improved blocks.

3. Although the resultant thermal transmittance of a wall depends on several parameters (type of block used, cavity size, mortar joints, constituent materials), test results showed that for any given type of block and assembly, the thermal transmittance of the wall depends mostly on the material's thermal conductivity ( $\mathrm{k}$-value).

4. The differences between the results obtained from the laboratory and in-situ heat flow meter testing were small (with a maximum difference of approximately $4.5 \%$ for single density blocks and $9 \%$ for double density blocks, when excluding the rather high value obtained for HCB-N6 result). For this reason, one could conclude that the in-situ test cell models were efficiently constructed to provide satisfactory setups for in-situ testing to be carried out such that results can be relevantly used for practical applications.

5. A rather significant difference and inconsistency was observed when comparing in-situ results obtained from the infrared method to the results obtained from the in-situ/laboratory heat flow meter methods. Although the IRM provides a quicker and easier method of data collection (based over a few hours as compared to a minimum of three days with the HFM method), it is 
clear that further improvement in the methodology currently available needs to be developed for it to be reliably used for on-site applications.

6. Results obtained through the numerical analysis, making use of the R-program, showed that for improved ARX-models, other weather variables such as wind and rain should be taken into consideration. This would give a more realistic picture of how building envelopes, insitu, behave when tested for thermal transmittance values.

7. Given the correct environmental conditions are available (a minimum temperature difference between the inside and outside surfaces of an $\mathrm{HCB}$ building envelope equal to $10^{\circ} \mathrm{C}$ ), the best way available to-date to evaluate the $\mathrm{U}$-value of building walls is by direct measurement with a heat flux meter. If the conditions are not ideal, then one might opt for the IRM which can then provide a relatively equivalent measurement of $\mathrm{U}$-value.

Complementary to the main conclusions of this research work, the following have been noted:

$>$ Satisfactory strength values of the loadbearing HCBs were achieved using the lightweight expanded clay aggregate in conjunction with the addition of increased cement content. Positive improvements in characteristic compressive strength were also observed for the modified mix HCB-8 when compared to the standard HCB-N5. However, other than for batches HCB-8 and HCB-10, compressive strengths of mixes with high LECA/cement ratios failed to reach the minimum standard characteristic compressive strength of $7.5 \mathrm{MPa}$ for loadbearing blocks (stipulated as a benchmark for this study). The research findings showed that it is possible to have ThermHCB units with up to $88 \%$ LECA/cement ratio used for loadbearing purposes in buildings without losing on the reference characteristic compressive strength value of $7.5 \mathrm{MPa}$.

$>$ Compressive strength values were compared with respective thermal transmittance values obtained from the data gathered and analysed using the three methods of measurement. It was noted that the compressive strengths increased in value with higher cement ratios whilst thermal conductivity was seen to decrease with a higher lightweight expanded clay aggregate (LECA)/cement ratio. A balance had to be reached in order to obtain the minimum improved thermal HCBs whilst achieving the minimum compressive strength required for structural applications. Other mixes that produced improved heat insulation properties could still be considered for non-structural applications. The optimized HCB-10 batch satisfied the minimum characteristic strength benchmark of $7.5 \mathrm{MPa}$ and thus was classified as the batch having sufficient strength to be accepted as a load-bearing HCB.

Whilst general findings in this study reflect and enhance numerical simulations, it would be beneficial to run experimental investigations parallel to specific on-site projects with various masonry blocks and different construction systems (available locally on the market). In this way, more precise quantification of the accuracy of the methods used can be obtained. Building an in-use database can help assess the real saving potential of proposed thermally improved building materials and their contribution to national energy saving targets. This can therefore highlight where future government subsidies should be focused.

\section{Acknowledgements}

We would like to acknowledge the National Research and Innovation Programme 2012 of the Malta Council for Science and Technology (MCST), for co-financing this project under grant agreement R\&I-2012-058, the Institute for Sustainable Energy of the University of Malta for providing the necessary research environment, and Mr Manuel Aquilina and Mr Malcolm Farrugia from the 


\section{ACCEPTED MANUSCRIPT}

Institute for Sustainable Energy of the University of Malta, who have helped in the construction of the in-situ test cells, wiring of sensors and programming of data loggers.

\section{References}

[1] C. Caruana, Master of Science (by research) Thesis, Institute for Sustainable Energy, University of Malta (2015), Determination of Thermal Characteristics of Standard and Improved Hollow Concrete Blocks using Different Measurement Techniques.

[2] International Energy Agency (IEA) Energy Conservation in Buildings and Community Systems Programme (ECBCS) Annex 58 (2016), http://www.just-pm.eu/dynastee/ Reliable building energy performance characterisation based on full scale dynamic measurements.

[3] P. Fazio et al., Buildings III Proceedings 1985, http://web.ornl.gov/sci/buildings, Simplified Procedure to Estimate the Dynamic Thermal Performance of Existing Walls, paper 18.

[4] Bulent Yesilata et al., Energy and Buildings 2007, A simple dynamic measurement technique for comparing thermal insulation performances of anisotropic building materials, pp. 1027-1034.

[5] Aimee Byrne et al., Energy and Buildings 2013, Transient and quasi-steady thermal behaviour of a building envelope due to retrofitted cavity wall and ceiling insulation, pp. 356-365.

[6] Fang et al., Buildings III Proceedings (1985), http://web.ornl.gov/sci/buildings, The Assessment of Accuracy of the In-Situ Methods for Measuring Building Envelope Thermal Resistance, paper 49.

[7] P. Baker, Historic Scotland Technical Paper 10 (2010), Glasgow Caledonian University, https://www.historicenvironment.scot/archives-and-

research/publications/publication/?publicationId=16d0f7f7-44c4-4670-a96b-a59400bcdc91

[8] S. Pulis, The Thermal Properties of Concrete Blockwork, BE\&A Dissertation, University of Malta (1992).

[9] N. Vella, Thermal Properties of Insulated Concrete Blocks, BE\&A Dissertation, University of Malta (2010).

[10] R. Becker, Buildings X Proceedings (2007) http://web.ornl.gov/sci/buildings, Air Permeability and Thermal Performance of Concrete Block Wall Sections, paper 23.

[11] S. Kato et al., Method of in-situ measurement of thermal insulation performance of building elements using infrared camera.

[12] J. Thouvenel, Master of Science Thesis, KTH School of Industrial and Management Energy Technology, Stockhom (2012), Find a modern and quick method to determine the U value and the thermal characteristics of a building envelope using an IR camera.

[13] M.P. Morales et al., Energy and Buildings, Vol. 69, 2014, Possibilities for improving the equivalent thermal transmittance of single-leaf walls for buildings, pp. 473-480.

[14] P. Bacher et al., Energy and Buildings (2011), doi: 10.1016/j.enbuild.2011.02.005, Identifying suitable models for the heat dynamics of buildings.

[15] Mathews, P.G. (2004), Design of Experiments with MINITAB, American Society of Quality, Quality Press, Milwaukee, Wisconsin.

[16] C. Caruana et al., Sustainable Energy 2015: The ISE Annual Conference, Development of a thermally improved hollow concrete block.

[17] C. Caruana et al., Energy Procedia 2014 ( Vol 62), Overview of testing methodologies for thermally improved hollow-core concrete blocks, pp. 180-189.

[18] Document F, Technical Guidance Conservation of Fuel, Energy and Natural Resources (Minimum Requirements of Energy Performance of Building Regulations 2006), Services Division Building Regulations Office, Malta.

[19] Giuseppe Desogus et al., Energy and Buildings 2011, Comparing different approaches to in-situ measurement of building components thermal resistance, pp. 2613-2620.

[20] R. Curmi et al., ITC User Conference 2014, Comparison of thermal transmittance of in-situ HCB walls as determined by infrared and heat flow testing methods. 


\section{ACCEPTED MANUSCRIPT}

[21] H. Madsen et al., Thermal Performance Characterization using Time Series Data 2015. http://orbit.dtu.dk/en/publications/thermal-performance-characterization-using-time-series-data--ieaebc-annex-58-guidelines(efa4fbc1-f244-4955-9c89-9305fee3993b).html.

[22] Yesilata et al., Energy and Buildings 2007, A simple dynamic measurement technique for comparing thermal insulation performances of anisotropic building materials, pp. 1027-1034.

[23] R Core Team (2016), R: A language and environment for statistical computing. $R$ foundation for Statistical Computing, Vienna, Austria. URL https://www.R-project.org/.

\section{HIGHLIGHTS}

- A new hollow concrete block has been manufactured and tested for thermal and structural characterisation

- Results have shown that the new block has achieved $21 \%$ improved thermal insulation, while keeping the compressive strength unchanged, when compared to a standard locallymanufactured HCB. The weight of the new block has also dropped by $24 \%$, which makes it easier for builders to handle and reduce construction time.

- The paper has also compared results of thermal testing using different methodologies both in a laboratory setup and in-situ test conditions. The differences between the results obtained from the laboratory and in-situ heat flow meter testing were small (with a maximum difference of approximately $4.5 \%$ for single density blocks and $9 \%$ for double density blocks. On the other hand, a rather significant difference and inconsistency was observed when comparing in-situ results obtained from the infrared method to the results obtained from the in-situ/laboratory heat flow meter methods.

- Results obtained through the numerical analysis, making use of the R-program, showed that for improved ARX-models, other weather variables such as wind and rain should be taken into consideration. This would give a more realistic picture of how building envelopes, insitu, behave when tested for thermal transmittance values. 